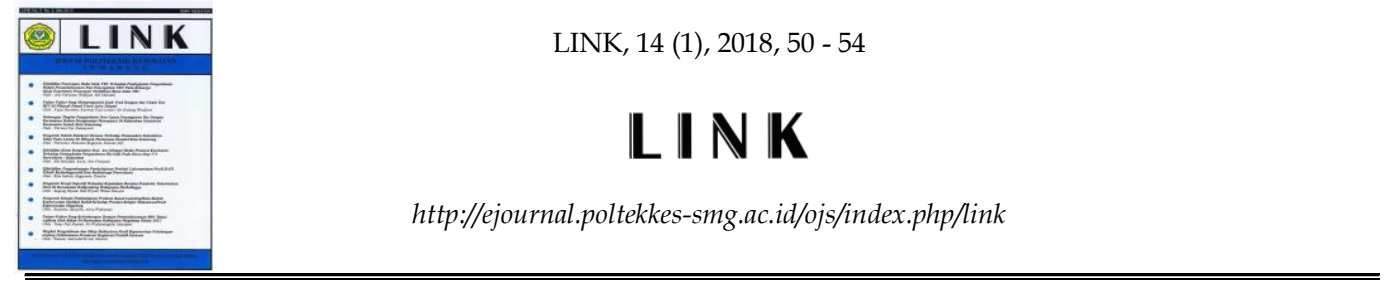

\title{
SKRINING DAN PENDAMPINGAN PENCEGAHAN PENYAKIT TIDAK MENULAR DI MASYARAKAT
}

\author{
Nina Indriyawati*); Widodo; Melyana Nurul; Djoko Priyatno; Marichatul Jannah \\ Jurusan Keperawatan Semarang; Poltekkes Kemenkes Semarang \\ Jl. Tirto Agung ; Pedalangan ; Banyumanik; Semarang
}

\begin{abstract}
Abstrak
Semakin meningkatnya kejadian PTM, maka perlu adanya edukasi dan pendampingan kepada masyarakat untuk melaksanakan deteksi dini atau skrining terhadap PTM, terutama pada kelompok yang berisiko. Sasaran pada kegiatan pengabdian kepada masyarakat ini adalah masyarakat yang beresiko dan usia lanjut sebanyak 150 orang di Kabupaten Demak, Kecamatan Gubug Kabupaten Grobogan, dan Kecamatan Pudak Payung. evaluasi dilakukan dengan memberikan kuesioner tentang tingkat pengetahuan dan pemantauan hasil laboratorium, dan tekanan darah. Evaluasi akan diukur dari tingkat pengetahuan sebelum dan sesudah diberikan pendidikan kesehatan. Peningkatan PTM dapat ditekan melalui pengendalian factor risiko yaitu pengurangan konsumsi rokok, alkohol, gula dan garam, peningkatan konsumsi buah dan sayur, meningkatkan aktifitas fisik melalui olah raga, mencegah kegemukan, pengendalian stress dengan kegiatan rekreasi serta melakukan pemeriksaan tekanan darah, kadar gula darah secara teratur. Upaya pencegahan PTM dapat dilakukan oleh masyarakat secara mandiri melalui kegiatan Posbindu.
\end{abstract}

Kata kunci: Skrining ; Pendampingan ; Penyakit Tidak Menular

\begin{abstract}
[SCREENING AND ASSISTANCE NOT INFECTIOUS DISEASE PREVENTION IN THE COMMUNITY]Increasing the incidence of PTM, it is necessary for education and assistance to the community to carry out early detection or screening of PTM, especially in groups at risk. The target of this community service activity is risky and elderly people as much as 150 people in Demak District, Gubug Sub-district Grobogan District, and District Pudak Payung. evaluation is done by providing a questionnaire about the level of knowledge and monitoring of laboratory results, and blood pressure. Evaluation will be measured from the level of knowledge before and after health education. Increased PTM can be suppressed through the control of risk factors, namely reduction of cigarette, alcohol, sugar and salt consumption, increased consumption of fruits and vegetables, increase physical activity through exercise, prevent obesity, stress control with recreational activities and check blood pressure, regular. Efforts to prevent PTM can be done by the community independently through Posbindu activities.
\end{abstract}

Keywords: Accompaniment ; Non-Communicable Disease

\section{Pendahuluan}

Berdasarkan data yang dihimpun Kemenkes, pada 1990, angka kematian akibat PTM di Indonesia berada pada angka 37\%. Angka tersebut terus mengalami kenaikan. Pada 2000, kematian akibat PTM menjadi 49\%.
Selanjutnya pada 2010 angka tersebut kembali meningkat menjadi 58\%. Terakhir, hingga pertengahan 2015, diketahui kematian akibat PTM telah mencapai 57\% (Kemenkes, 2017). Ada 10 penyakit penyebab terbesar kematian yakni stroke, kecelakaan lalu lintas, jantung iskemik,

\footnotetext{
*) Nina Indriyawati

E-mail: ninagading@hotmail.com
} 
Tabel 1. Karakteristik Kelompok beresiko

\begin{tabular}{|c|c|c|c|}
\hline No. & Karakteristik & Frekwensi (n) & Prosentase $(\%)$ \\
\hline \multirow[t]{3}{*}{1} & Jenis Kelamin & & \\
\hline & A. Laki-Laki & 36 & 44 \\
\hline & B. Perempuan & 44 & 56 \\
\hline \multirow[t]{4}{*}{2} & Usia & & \\
\hline & A. $40-50$ tahun & 34 & 43 \\
\hline & B. 51-60 tahun & 19 & 23 \\
\hline & C. $>61$ tahun & 27 & 34 \\
\hline \multirow[t]{4}{*}{3} & Kepercayaan/agama:। & & \\
\hline & $\begin{array}{ll}\text { a. } & \text { Islam } \\
\end{array}$ & 73 & 91 \\
\hline & $\begin{array}{ll}\text { b. } & \text { Kristen }\end{array}$ & 5 & 6 \\
\hline & c. Katolik & 2 & 3 \\
\hline \multirow[t]{3}{*}{4} & Status perkawinan & & \\
\hline & $\begin{array}{ll}\text { a. } & \text { Suami/istri }\end{array}$ & 62 & 78 \\
\hline & $\begin{array}{ll}\text { b. } & \text { Janda/Duda }\end{array}$ & 18 & 22 \\
\hline
\end{tabular}

kanker, diabetes melitus, tuberkulosis, infeksi saluran pernafasan atas, depresi, asfiksia dan trauma kelahiran serta penyakit paru obstruksi kronis. Perubahan fenomena ini terjadi akibat perilaku dalam menjalankan pola hidup sehat. Warga mengantisipasi penyakit menular, namun mengabaikan perilaku yang berdampak pada munculnya penyakit tidak menular yang juga memicu kematian (Antara, 2017).

Perlunya kegiatan yang menggerakkan dan memotivasi masyarakat untuk hidup sehat dan mengubah gaya hidup, yaitu dengan Gerakan Masyarakat Sehat atau Germas. Germas harus terus digalakkan untuk meningkatkan kesadaran masyarakat menjalankan pola hidup sehat. Pencegahan jauh lebih baik dibanding melakukan pengobatan ketika sudah terjangkit penyakit.(Antara, 2017).

Semakin meningkatnya kejadian PTM, maka perlu adanya edukasi dan pendampingan kepada masyarakat untuk melaksanakan deteksi dini atau skrining terhadap PTM, terutama pada kelompok yang berisiko. Masyarakat harus selalu diajak untuk mengenali penyakitnya. Penting untuk melaksanakan pengabdian kepada masyarakat tentang skrining dan pendampingan pencegahan Penyakit Tidak Menular di masyarakat.

\section{Metode}

Sasaran pada kegiatan pengabdian kepada masyarakat ini adalah masyarakat yang beresiko dan usia lanjut sebanyak 150 orang di Kabupaten Demak, Kecamatan Gubug Kabupaten Grobogan, dan Kecamatan Pudak Payung.

Metode yang dipergunakan adalah skrining, edukasi dan pendampingan yang terdiri dari:

1) Metode edukasi: memberikan pendidikan kesehatan pada kelompok resiko dan lansia terkait dengan isu pencegahan PTM dan Gerakan Masyarakat hidup sehat (Germas).

2) Metode Demonstrasi: mendemonstrasikan gerakan gerakan senam yang diikuti oleh peserta.

3) Metode skrining: Melakukan pemeriksaan Tekanan Darah, Berat Badan, gula darah, cholesterol, asam urat pada kelompok resiko dan lansia.

Rancangan evaluasi dilakukan dengan memberikan quesionaire tentang tingkat pengetahuan dan pemantauan hasil laboratorium, dan tekanan darah. Evaluasi akan diukur dari tingkat pengetahuan sebelum dan sesudah diberikan pendidikan kesehatan.

\section{Hasil dan Pembahasan}

Pengabdian kepada masyarakat skrining pada kelompok resiko dilaksanakan pada bulan Februari sampai Agustus 2017. Kelompok beresiko dan lansia yang ikut berpartisipasi dalam kegiatan tersebut berkisaran 40 tahun keatas dari tiga tempat yang berbeda yaitu Grobogan (20 orang), Demak (35 orang), Pudak Payung (25 orang). Kegiatan yang dilaksanakan dalam pendampingan tersebut adalah untuk mengetahui kondisi kesehatan kelompok beresiko dan lansia terkait penyakit tidak menular.

\section{Karakteristik Kelompok Beresiko}

Karakteristik kelompok beresiko meliputi jenis kelamin, usia, kepercayaan/agama, dan status perkawinan yang dijelaskan pada tabel 1 . Dari tabel 1 di dapatkan bahwa berdasarkan jenis kelamin mayoritas kelompok sasaran 44 orang $(56 \%)$ dan laki-laki sebanyak 36 orang (44\%). Mayoritas kelompok sasaran berusia 40-50 tahun (43\%), dengan memluk agama Islam 
(91\%). Status pernikahan kebanyakan kelompok sasaran masih memiliki pasangan (78\%).

Tabel 2. Pemantauan Kesehatan Lansia di lihat dari Tekanan Darah, Berat Badan, Asam Urat dan Gula Darah Sewaktu

\begin{tabular}{clcc}
\hline No. & \multicolumn{1}{c}{ Pemeriksaan Kesehatan } & Frekuensi (n) & Prosentase (\%) \\
\hline 1 & Berat Badan & & 81 \\
\hline & a. Ideal & 48 & 19 \\
\hline & b. Gemuk & 32 & 31 \\
\hline Tekanan Darah & & 44 \\
\hline & a. Rendah & 25 & 25 \\
\hline & b. Normal & 35 & 66 \\
\hline & c. Tinggi & 20 & 34 \\
\hline Kadar Asam Urat & & \\
\hline & a. Normal & 53 & 73 \\
\hline b. Tinggi & Gula Darah Sewaktu & 27 & 27 \\
\hline & a. Normal & 58 & \\
\hline & b. Tinggi & 22 & \\
\hline
\end{tabular}

Skrining Penyakit Tidak Menular

Skrining dilakukan dalam satu waktu untuk memeriksa Tekanan Darah, Berat Badan, asam urat dan Gula Darah Sewaktu. Hal ini bisa dilihat dari table 2.

Dari Tabel 2 dapat dilihat bahwa kelompok resiko mempunyai berat badan lebih sebanyak $19 \%$, tekanan darah relative tinggi sebanyak $25 \%$, Kadar Asam Urat relative diatas normal sebanyak 34\% dan Gula Darah Sewaktu relative diatas normal sebanyak $27 \%$.

Menteri Kesehatan RI juga mengemukakan bahwa program pengendalian diabetes mellitus dilaksanakan secara integrasi dalam program pengendalian PTM terintegrasi yaitu dengan pendekatan faktor risiko PTM terintegrasi di fasilitas layanan primer, Pos Pembinaan Terpadu PTM (Posbindu PTM) dan CERDIK [C=Cek faktor risiko PTM (obesitas, hipertensi, hiperglikemi, hiperkolesterol) secara rutin dan teratur, $\mathrm{E}=$ Enyahkan asap rokok dan polusi udara lainnya, $\mathrm{R}=$ Rangsang aktifitas dengan gerak olah raga dan seni, $\mathrm{D}=$ Diet yang sehat dengan kalori seimbang (cukup sayur-buah, batasi gula garam-lemak), I= Istirahat yang cukup dan $\mathrm{K}=$ Kuatkan Iman dalam menghadapi stres)] serta patuh di Posbindu dan Balai Gaya Hidup Sehat (Infodatin, 2014).

\section{Pendidikan Kesehatan Penyakit Tidak Menular}

Dengan bertambahnya usia, struktur dan fungsi sistem tubuh manusia akan berubah baik fisik, mental, sosial maupun emosional. Hal ini tentu akan mempengaruhi kualitas kesehatan. Oleh karena itu perlu adanya suatu upaya untuk mencegah atau mempromosikan perubahan perilkau hidup sehat untuk meningkatkan kulitas hidup. Upaya yang dapat dilakukan yaitu dengan pendidikan kesehatan. Pendidikan kesehatan yang dapat dilakukan diantaranya:

\section{Pendidikan kesehatan tentang Mencegah stress}

Sehat adalah keadaan sejahtera fisik, mental, dan sosial secara utuh, yang tidak semata-mata bebas dari penyakit atau kecacatan (WHO, 2013). Ketika seseorang mengalami stres maka tubuh akan memproduksi hormon yang dapat meningkatkan tekanan darah, peningkatan tekanan darah inilah yang memicu terjadinya komplikasi hipertensi (Gunawan 2001). Oleh karena itu pendidikan kesehatan perlu dilakukan kepada kelompok beresiko agar dapat mengantisipasi dan mengendalikan stress. Pendidikan kesehatan yang dilakukan diantaranya dengan memberikan informasi tentang mengenal stress dan coping mecanism.

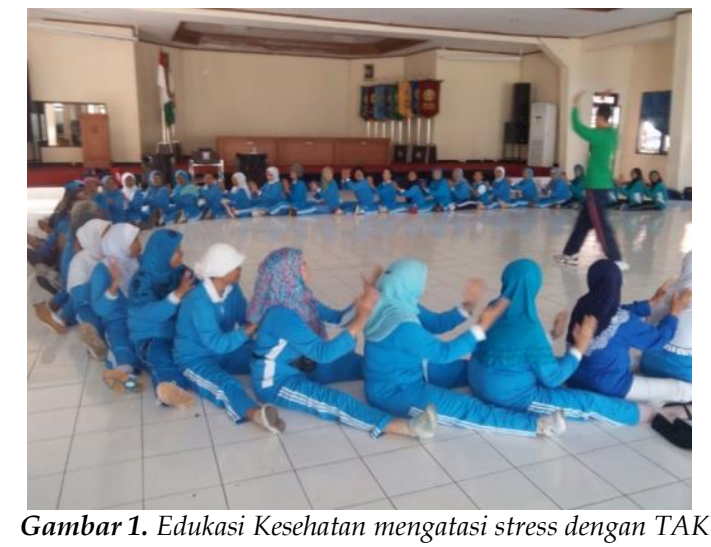

Pendidikan kesehatan tentang latihan dan olah raga untuk mencegah PTM

Semakin bertambahnya usia maka fungsi tubuh juga akan mengalami penurunan. Banyak orang yang mengeluh mengalami kesulitan dan tidak punya waktu dalam melakukan aktivitas 
atau olah raga dikarenakan tidak punya waktu atau fungsi otot mereka mengalami penurunan fungsi. Oleh karena itu diperlukan upaya untuk-

Gambar 2. Aktifitas senam dan peregangan

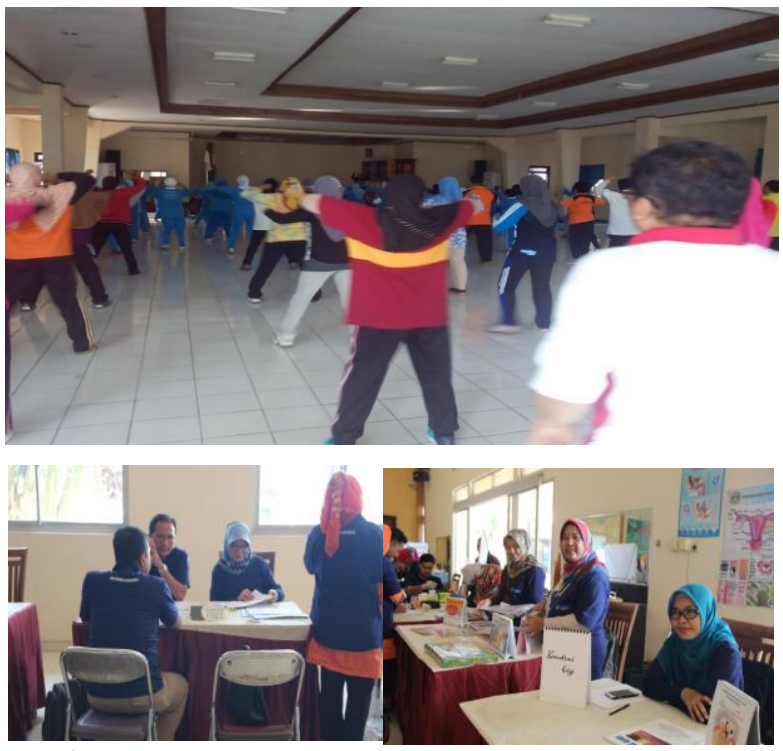

Gambar 3. Konsuling kesehatan

melatih otot-otot tubuh agar tidak kaku dan tetap bugar. Riskesdas tahun 2007 menyatakan bahwa 48.2 persen penduduk Indonesia yang berusia lebih dari 10 tahun kurang melakukan aktivitas fisik, dimana kelompok perempuan yang kurang melakukan aktivitas fisik (54.5 persen) lebih tinggi dari pada kelompok laki-laki $(41,4$ persen). Selain itu kurang melakukan aktivitas fisik didaerah rural sebesar 42,4 persen sementara didaerah urban kurang melakukan aktivitas fisik telah mencapai 57,6 persen. Masyarakat sadar bahwa dengan meningkatkan aktivitas fisik dengan cara latihan fisik atau olahraga yang teratur dapat meningkatkan derajat kesehatan. Tetapi masih banyak masyarakat belum paham bahwa latihan fisik atau berolahraga yang baik, benar, terukur, dan teratur akan meningkatkan kebugaran jasmani yang penting untuk menjaga stamina tubuh. Jadi tingkat kebugaran jasmani yang baik akan menurunkan angka kesakitan (Kemenkes, 2011).

\section{Pendidikan kesehatan tentang Diet}

Pengetahuan masyarakat untuk memilih makanan yang cukup dan seimbang untuk individu dan keluarga masih kurang. Hal ini sangat dipengaruhi oleh tingkat pendidikan, sosial ekonomi dan budaya (Kemenkes RI, 2011). Pendidikan kesehatan tentang Cek Kesehatan secara Rutin
Pengendalian PTM dapat dilakukan dengan melakukan modifikasi factor risiko dengan perubahan perilaku yang dikenal dengan akronim CERDIK. Kegiatan CERDIK harus dilakukan secara rutin dan berkesinambungan sebagai berikut :

C: Cek kondisi kesehatan anda secara rutin dan teratur

E : Enyahkan asap rokok dan polusi udara lainnya

$\mathrm{R}$ : Rajin aktifitas fisik dengan gerak olah raga dan seni

D : Diet yang sehat dengan kalori seimbang (rendah gula, garam dan lemak serta kaya serat)

I : Istirahat yang cukup dan utamakan keselamatan

K: Kendalikan stres dan tindak kekerasan

\section{Simpulan dan Saran}

\section{A. Kesimpulan}

Telah terjadi peningkatan penyakit tidak menular yang memerlukan perhatian serius oleh semua pihak baik pemangku kebijakan maupun masyarakat. Peningkatan PTM dapat ditekan melalui pengendalian factor risiko yaitu pengurangan konsumsi rokok, alcohol, gula dan garam, peningkatan konsumsi buah dan sayur, meningkatkan aktifitas fisik melalui olah raga, mencegah kegemukan, pengendalian stress dengan kegiatan rekreasi serta melakukan pemeriksaan tekanan darah, kadar gula darah secara teratur. Upaya pencegahan PTM dapat dilakukan oleh masyarakat secara mandiri melalui kegiatan Posbindu.

\section{B. Saran}

Perubahan perilaku sehat hanya bisa dilakukan oleh masyarakat sendiri. Dan masyarakat harus menjadi agent of change yang akan mempengaruhi kelompoknya. Pemberdayaan masyarakat perlu ditingkatkan untuk menggerakkan dan membudayakan perilaku hidup sehat seperti layanan masyarakat yang sudah ada yaitu Posbindu, yang harus memperluas jangkauannya tidak hanya pada kelompok beresiko dan dewasa tua. Tetapi Posbindu juga harus menjangkau kelompok laiinya dan usia muda. Selain itu perlu juga digalakkannya layanan mandiri kesehatan masyarakat di paguyuban atau forum yang ada.

\section{Ucapan Terima Kasih}

Terima kasih kepada Direktur Poltekkes Kemenkes Semarang, DIPA Poltekkes Kemenkes 
Semarang yang telah mendanai pengabmas ini, Tim penyusun pengabmas dan semua pihak yang terlibat dalam pengabmas ini.

\section{Daftar Pustaka}

1. World Health Organization; 2015 [diakses tanggal 21 Februari 2017]. Tersedia dari: http://www.who.int/mediacentre/facts heets/fs355/en/

2. Kementrian Kesehatan Republik Indonesia. Buletin Jendela Data dan Informasi Kesehatan Penyait Tidak Menular. Jakarta: Pusat Data dan Informasi Kementrian Kesehatan RI; 2012. hlm. $1-28$.

3. Anies. Waspada Ancaman Penyakit Tidak Menular: Solusi Pencegahan Aspek Perilaku \& Lingkungan. Jakarta: PT. Elex Media Komputindo; 2003.

4. World Medical Association, Inc; 2015 [21 Februari 2017]. Tersedia dari: http:/ / www.wma.net/en/20activities/3 0

publichealth/10noncommunicablediseas e s/index.html

5. The Jakarta Post; 2011 [diakses tanggal 21 Februari 2017]. Tersedia dari: http://www.thejakartapost.com/news/2 011/06/23/indonesia-loses-billions-diabe tes-chronic-diseases.html

6. World Health Organization; 2015 [diakses tanggal 21 Februari 2017]. Tersedia dari: http://www.who.int/nmh/publications / fact_sheet_cardiovascular_en.pdf?ua=17

7. World Health Organization; 2015 [diakses tanggal 21 Februari 2017]. Tersedia dari: http://www.who.int/nmh/publications

/fact_sheet_cancers_en.pdf?ua $=1$

8. World Health Organization; 2015 [diakses tanggal 21 Februari 2017]. Tersedia dari: http:/ / www.who.int/nmh/publications /fact_sheet_respiratory_en.pdf?ua $=1$

9. World Health Or ganization; 2015 [diakses tanggal 21 Februari 2017]. Tersedia dari: http:/ / www.who.int/nmh/publications / fact_sheet_diabetes_en.pdf?ua $=1$

10. Fatimah RN. Diabetes Melitus Tipe 2. J Majority. 2015;5(4):93-101.

11. Hunter DJ dan Reddy KS. Noncommunicable Diseases. N Engl J Med. 2013; 369(14):1336-1343.

12.Vaibhav Khandelwal. Global Intervention for Prevention and Control of Noncommunicable Diseases. International Journal of Medical Science and Public Health. 2013;2(4):780-784.

13. Antara, 2017. Kemenkes: Penyakit tidak Menular Mendominasi Penyebab Kematian,

di akses pada Antaranews,com, tanggal 12 Agustus 2017

14. Kemenkes, 2017. Gaya Hidup Penyebab Kematian Kian Dominan. [Diakses tanggal,

21 Februari 2017]. Tersedia dari http:/ / pptm.depkes.go.id/cms/frontend $/ ? \mathrm{p}=$ infoslide\&id $=43$

15. Gunawan, Lany, 2001, Hypertensi, Yogyakarta, Kanisius

16. Kementerian Kesehatan RI. 2011, Strategi nasional penerapan pola konsumsi makanan dan aktifitas fisik untuk mencegah penyakit tidak menular, Jakarta 